\title{
Effort and Reward Effects: Appreciation and Self-Rated Performance in e-Internships
}

\author{
Debora Jeske $^{1, *}$ (D) and Carolyn M. Axtell ${ }^{2}$ \\ 1 School of Applied Psychology, University College Cork, Cork T23 K208, Ireland \\ 2 Institute of Work Psychology, University of Sheffield Management School, Sheffield S10 2TN, UK; \\ c.m.axtell@sheffield.ac.uk \\ * Correspondence: d.jeske@ucc.ie; Tel.: +353-21-490-3000
}

Received: 12 November 2017; Accepted: 14 December 2017; Published: 20 December 2017

\begin{abstract}
As new work and internship options arise, educators, employers and students seek information about the learning benefits of these new arrangements. This is also the case in terms of e-internships. The purpose of this study was to assess the merit of the effort-reward imbalance model to understand appreciation and performance as reported by the e-interns (also known as virtual interns). The study involved a cross-sectional sample of e-interns. The sample was recruited using the snowball technique and two specialized internship portals. Participants were grouped into a number of conditions. Effort conditions depended on participants' reported goal clarity and satisfaction with support. Reward conditions were determined based on the (un-)availability of training and payment in e-internships. When participants fell into high effort or low reward conditions, they reported lower perceived performance. They also felt less valued. The reverse pattern was observed when participants completed their internship under low effort and high reward conditions. By identifying conditions under which e-interns will report higher performance and appreciation, employers are provided with starting points for the design and reward practices. In addition, the results suggest that e-internships may share similar characteristics of traditional internships which may similarly vary in terms of the value and rewards they bring to interns.
\end{abstract}

Keywords: virtual internship; e-internship; effort-reward imbalance; performance

\section{Introduction}

The adoption of new computer tools and virtual forms of communication has led to the emergence of many different forms of working. From tele-working, to virtual work, and the emergence of electronic Human Resource Management. In addition, our notions of work environments have changed, most recently many cities have embraced co-working facilities, designated spaces that provide an 'office' like environment to virtual workers. However, our experience reports with internship providers and educators have shown that some of these developments have not been embraced as readily. One case in point are e-internships (also known as virtual environments).

Many educators, employers and students unfamiliar with this form of internship or the internship providers are hesitant to recognize the value or learning benefit of such internships. They are often considered as less valuable as actual traditional internships on the site of an organization. These concerns have a number of negative outcomes. First, in some fields, e-internships may be the best and often most affordable opportunity for people to gain experience in a certain field (e.g., marketing, branding, software design, website design). Yet due to the lack of familiarity with and experience of many educators, such hours and projects completed as part of e-internships are often not eligible for academic credit. Second, many small and medium-sized employers and those in remote areas often need e-interns to help them with specific projects (e.g., development of customer care databases, 
websites, or marketing strategies). Their efforts to recruit e-interns are often thwarted by concerns about the value of such internships and the unknown learning potential of such internships, both for the e-interns and the employers (Jeske and Axtell 2016a, 2016b). In order to address these concerns and educate both employers and educators about the actual experience of interns (see also (Jeske and Axtell 2014)), the present report outlines some findings about the learning and reward experiences of e-interns in a number of different domains. We hope to make a positive contribution to educators and employers and thus encourage the recognition (and possibly accreditation) as well as wider adoption of e-internships.

\subsection{Expectations and e-Internships}

Expectations about effort and outcomes of activities play an important role in the workplace. The extent to which the work and effort invested in an individual is perceived to result in the desired results shapes both motivation and persistence on the task. These assumptions are captured in the expectancy framework. This theory was originally developed by Victor Vroom (Vroom 1964) to understand work motivation. The main questions of this framework focus on the factors that determine work motivation. These factors include beliefs regarding the anticipation that effort leads to certain levels of outcomes (expectancy), the belief that performance will lead to rewards (instrumentality), and that the rewards will be appreciated and of value to the recipient (valence). Expectancy theory (Vroom 1964) therefore considers that individuals join employers with expectations, and that individuals will identify as well as choose the alternatives that will optimize their outcomes for them as individuals (see also (Lunenburg 2011)). Effort in this paper is considered as the amount of energy that is expended to achieve a given activity, which may furthermore depend on the circumstances leading to the activity and the rewards that individuals expect in return (Mullins and Christy 2016). We consider rewards to be desirable outcomes, which may take the form of intrinsic rewards such as a sense of achievement or recognition, as well as extrinsic rewards or remuneration (Mullins and Christy 2016).

The importance of these factors has been studied in relation to a number of settings. We propose that expectations about effort and reward are likely to play a role in internship settings. Specifically, however, in computer-mediated internships known as virtual or e-internships. The rationale for this proposition is based on the following: Virtual settings lack the usual transparency and immediacy of feedback that is part of regular workplaces. In regular workplaces, employees and interns are able to see how supervisors react to their work examples and interact with their supervisors to gain feedback. In addition, the supervisor is able to note the effort that individuals invest in their work and may be able to support their performance by noting when the employee or intern needs support. These circumstances may strengthen the relationship between expectations, performance, and outcomes (such as rewards, payments, or bonuses). At the same time, regular employees and interns in traditional settings are able to assess the equity of the rewards provided in return for their input (e.g., overpayment, underpayment, or equitable payment).

In the context of virtual or e-internships, the interns may not have access to the same support mechanisms due to both temporal and geographic separation from their supervisors or peers. Such separation is important to note since research has shown that feedback from multiple sources, such as co-workers and supervisors, is received more positively when the recipients of the feedback feel supported in their development (Mabey 2001). Separation from others may be particularly the case for e-interns when the organization is located in another country and time zone. This may generate new uncertainties and ambiguities. Role ambiguity, in particular, has been noted as a workplace stressor (Ayyagari et al. 2011). Role ambiguity may be particularly transferable to e-internships as the interns are less likely to have regular inductions and may face significant ambiguity due to their lack of work experience and the reliance on computer-mediated interactions. However, ambiguity may be reduced by frequent interactions with supervisors that provide individuals with structure and standards, all of which will facilitate team work (see also (Rizzo et al. 1970)). In addition, they may potentially lack 
information to assess how equitable their rewards are, or how to assess how much effort is required to meet or exceed performance- unless the supervisors clearly communicate expectations to inform effort. In addition, the value of the rewards may not be something they are able to negotiate, which means reward preferences may not be met or negotiable.

A pertinent contribution in the research on effort-performance-reward links is the work by Siegrist (1996). He argues that reciprocity (or the lack thereof) is critical. The potentially positive effects of work for employees' emotional or motivation self-regulation may be negated when the efforts are not reciprocated (e.g., in the form of money, esteem, or status; (Siegrist 1996)). To date, most of the work on the effort-reward imbalance model has been on the effects of these conditions for the well-being (De Jonge et al. 2000) and various other health outcomes of employees (Siegrist 1996; see also review by (Van Vegchel et al. 2005; Tsutsumi and Kawakami 2004)), although some work has also considered the implications for organizational citizenship behaviors at work (Korsgaard et al. 2010).

High effort conditions include situations where employees face significant extrinsic demands or obligations, requiring significant intrinsic effort to cope. When these are combined with low reward conditions, employees may experience significant negative outcomes. In other words, the effort and reward conditions combine in ways that can lead to negative implications for individuals. In the context of work, these implications may also affect not only performance but also how valued individuals feel by their employer. This connection links Siegrist's model (Siegrist 1996) to the valence factor of expectancy theory (Vroom 1964).

\subsection{Effort and Reward in e-Internships}

The question arises whether or not the findings of low effort and high reward conditions also apply to and have effects on the experience of e-interns. The rationale for applying the reward-imbalance model to e-internships is based on the following argument. First, Siegrist (1996, p. 30) noted a number of conditions where rewards and efforts are unbalanced. He noted that in situations where individuals have "low occupational status control in combination with higher effort, basic reciprocity of costs and gains are lacking" (Siegrist 1996, p. 30). These circumstances are readily applicable to e-interns that lack control and job security, have generally lower occupational status, and may have to engage in significant effort to learn and perform in order to meet performance expectations. In addition, experiences of high effort and low rewards have been linked to longer sickness absence duration and more frequent absences (Derycke et al. 2013). In the context of e-internships, these conditions may also result in similar effects, such as withdrawals from the internship or silent drop-outs.

However, one clarification applies: e-interns are usually not as embedded in organizations as regular employees, and their engagement with the internship provider tends to be temporary rather than longer-term. Different combinations of effort and reward are likely to influence perceptions of appreciation by the employer and one's perceived effectiveness and performance as an e-intern. For example, the degree to which effort is perceived as high may depend on the degree to which e-interns face ambiguities. Low effort conditions may involve situations where performance is readily achieved due to the frequent interaction with supervisors to clarify expectations, provide structure, feedback and provisions (including software and portals). Such circumstances may also maximize the expectancy of interns; as the support and provisions increase, so too does their perceived competence and ability to achieve the performance expected of them (see also (Rothmann and Cooper 2015)). High effort conditions may include situations where the e-intern faces significant uncertainty about their tasks and role, which is exacerbated by a lack of support.

Second, many of the assumptions behind the expectancy framework help to identify motivation and performance outcomes in e-internships as well. However, rather than linking effort to performance and rewards, we propose a different flow for our study. Many e-internships may not involve regular salaries, bonuses, or promotions. Rewards may be one-time payments. As a result, rewards are usually not shaped by performance per se. Instead, the e-internship may either be remunerated in some way or entirely unpaid. These conditions are usually set before the e-internship commences, and thus 
might not be the outcome of performance. This means that although effort and reward conditions are potential predictors of performance; rewards may not follow as a result of the effort that is invested and the performance that results.

Reward conditions in e-internships can be differentiated in terms of what is available (i.e., whether e-interns are paid and/or offered additional training). Specifically, when e-interns are provided remuneration and have access to training, they may also be considered as being in the higher reward condition. The concept of total rewards may furthermore be relevant here. Total rewards include other aspects of work than remuneration in that they can take the form of learning and development opportunities being made available to employees as well (CIPD 2014). Training has been recognized as one form of total reward that can be part of a strategic reward plan by the employer to complement financial remuneration (Chen and Hsieh 2006). The provision of training may further support their work efforts. In addition, receiving both remuneration and training may increase the perceived value of e-internships. When such provisions are lacking, individuals may be considered to work in low reward conditions. Two general research questions arise: What is the effect of low reward and high effort conditions during e-internships? Do any differences arise in terms of the degree to which e-interns feel valued during e-internships?

Along these lines we propose the following two hypotheses for how performance and appreciation are affected under different conditions, both in line with the effort-reward model literature to date: Appreciation (the feeling of being valued) and self-reported performance are predicted to be higher when e-interns are in a low effort compared to high effort condition (H1). In addition, the scores on the same outcome variables are predicted to be higher in the high reward compared to the low reward conditions (H2). When e-internship involve both low effort and high reward conditions, we expect appreciation and performance to be highest.

\section{Methods}

\subsection{Procedure}

Our dataset was a combination of two datasets, one collected in 2013 and 2015. The researchers contacted organizations and requesting the e-internship organizers to forward the survey to their interns. In addition, we posted the link to the survey on internship recruitment websites (one based in India and one based in the USA). Participation for all participants was voluntary and not remunerated. The survey was identical for both data collection rounds. Participants were first informed about the study purpose, requested to consent, and then asked to complete the survey sections. The survey included questions about each participant's background and e-internship experience to date (e.g., location, industrial sector, and remuneration). This also included questions on how they found and selected the internship, their tasks, the role requirements, supervision and work flexibility. In addition, participants were asked about their satisfaction with social support and mutual support, as well as their experience of training and mentoring. Finally, we asked them to evaluate their current experience, their general work preferences, and concluded the survey by collecting demographics (age, gender, children, and marital status).

\subsection{Participants}

The survey received 232 hits across two data collection efforts in 2013 and 2015. Of these, 171 individuals started the survey and gave consent. We excluded five participants who interacted mostly face to face with others (more than 90\%), which meant their internship experience did not fit that of a virtual internship. In addition, 10 cases were excluded due to dropping out in later stages of data collection. This resulted in a final sample of 158 participants (including 89 males and 68 females, plus one missing value). The age ranged from 16 to 50. Participants came from several different countries, with about half of them from India $(n=127)$. The other half came from a variety of different countries. This included twelve participants from the USA, 2 participants each for France, 
Nigeria, and Russia. One representative came from specific countries: Brazil, Canada, Ethiopia, Guyana, Hungary, Ireland, Lithuania, Switzerland, and United Kingdom (4 missing values). In terms of languages, 70 participants (44.3\%) spoke three languages fluently, 62 participants (39.2\%) spoke two languages, and 17 participants $(10.8 \%)$ indicated that they only spoke one language fluently. The large majority ( $n=122)$ were studying for a degree (or vocational certificate) at the time of the e-internship, while 28 were not studying. The duration of internships varied, from 2 up to 6 weeks $(n=48,30.4 \%)$, 6 to 12 weeks $(n=62,39.3 \%)$, and internships from 3 to 12 months $(n=30,19 \%)$. Only two individuals completed an e-internships of more than 12 months.

\subsection{Measures}

These included the determinants of effort and reward conditions, characteristics about e-internships, the e-internship experience, and demographics. Descriptive information is provided for each of the measures, also including psychometric information such as the unstandardized Cronbach's alpha for all scales.

\subsubsection{General Satisfaction with Support}

We also wanted to know how satisfied participants were in terms of the general support they had received from their supervisor, peers, and the communication structure (access to help). Answering responses ranged from (1) "very unsatisfied" to (4) "very satisfied". Following the replacement of some missing values (less than $10 \%)$, we computed a mean-centered composite $(\alpha=0.69, M=3.15, S D=0.54)$.

\subsubsection{Goal Clarity}

We asked our participants two goal clarity items from Szymanski et al. (2007). The items included: (1) "I was given clear objectives about what I needed to accomplish in my internship." And (2) "I was given clear descriptions of work I needed to complete in my internship." The response options ranged from (1) not at all to (5) to a great extent ( $r=0.725, p<0.001 ; M=3.36, S D=0.88)$.

\subsubsection{Feeling Valued (Appreciation)}

We also wanted to assess the extent to which e-interns felt appreciated (treatment as interns as "human capital" vs. cheap labor; (Lim and Morris 2006)). We asked our participants four questions that tried to capture appreciation of e-interns and value of the internship to participants. We used three items from the career instrumentality scale by Feldman et al. (1999). An example item is: "My work was strongly appreciated by my supervisor". The answering options ranged from (1) not at all to (5) to a very great extent. A mean-centered scale composite was created using the four items $(\alpha=0.78$, $M=3.31, S D=0.85$ ).

\subsubsection{Perceived Job Performance}

We also asked for a self-evaluation of job performance: "How would you describe your overall job performance (that is, the quality of your work)?" The original item came from Bergman et al. (2008). We included the 'quality of your work' to clarify what we meant. Responses ranged from (1) unsatisfactory to (4) excellent $(M=2.64, S D=0.74)$. Only 5 participants described their performance as unsatisfactory. An equal number described their performance as satisfactory $(n=67)$ or very satisfactory $(n=66)$, with 20 participants rating their performance as excellent.

\subsubsection{Training Available}

All participants were asked if they received training in your e-internship. The respondents had two answering options: Yes $(n=73,46.2 \%)$ and No $(n=85,53.8 \%)$. 


\subsubsection{Training Purpose}

Participants were asked to what extent the training aimed at improving specific skills and abilities. We included a number of options from which our participants could select their options. We also included an open response option. Training reportedly aimed at the following: (a) Improving technical job abilities $(n=44)$; (b) Improving employee interpersonal abilities, i.e., how well employees relate to one another $(n=24)$; (c) Remedying poor performance $(n=21)$; Preparing employees for future job assignments $(n=21)$; (d) Building/supporting teamwork within the company $(n=25)$; (e) Teaching each employee about the company's values and ways of doing things $(n=25)$; (f) Providing substantial training when employees first start work $(n=17)$; (g) Helping employees understand the business, e.g., knowledge of competitors, new technologies etc. $(n=31)$; (h) Providing employees with the skills needed to do a number of different jobs, not just one particular job $(n=31)$; and (i) other: Gaining management and supervision skills to manage a team. In addition, 107 out of 158 participants indicated that they had a mentor at work (defined in the survey as "somebody who counsels you during your internship, helping you improve your skills and become familiar with organizational functions").

\subsubsection{Remuneration}

On average, a third of participants were paid $(n=45,28.5 \%)$, the other two thirds were unpaid ( $n=106,67.1 \% ; 7$ missing values). The most common methods for finding e-internships relied on personal contact, online resources, specific internship sites, and college resources $(n=128)$.

\subsubsection{Upfront Information about Internship}

Participants were also asked "Please tell us how much information you had received about your e-internship before starting it." Answering options: (1) no information $(n=3)$; (2) some information $(n=63)$; (3) a lot of information $(n=69)$; (4) all necessary information $(n=20)$. Three participants have not answered this questions $(M=2.68, S D=0.72)$.

\subsubsection{Percentage of Time Spend Working Face-To-Face}

Information was gathered about the percentage of time spend working person-to-person or face-to-face (based on a measure by (Johnson et al. 2009)). We also asked participants to tell us about their organization's location, the type of organization in question, the industrial sector of the organization, size, their role in the internship, and remuneration practices of the organization. The percentage of face-to-face (in person) interactions varied widely: About half of participants spent less than $10 \%$ in face-to-face communication $(n=79,50 \%)$. One quarter spend between 10 to $50 \%$ face-to-face $(n=43,27.3 \%)$. The remaining 15 participants interacted face-to-face more than $50 \%$ of the time (21 missing values).

\subsubsection{Characteristics of the e-Internship Provider}

The e-internship providers were largely for-profit organizations $(n=117,74.1 \%)$, non-profits $(n=25,15.8 \%)$, and government organizations $(n=9,5.7 \%)$. The most popular sectors included e-internships in IT and telecommunication; advertising, marketing and public relations; education; banking and financial services $(n=70)$. The organizations tended to be of varying size, including employers with up to 20 employees ( $n=41,25.9 \%$ ), up to 49 employees ( $n=25,15.8 \%$ ), up to 199 employees ( $n=29,18.4 \%)$, and even up to 500 employees $(n=18,11.4)$. A last quarter was working for large organizations with more than 500 employees ( $n=37,23.4 \% ; 8$ missing values).

\subsubsection{Demographics}

Demographics included information on gender, age, nationality, disability and marital status. A small number of participants were married or in a committed relationship $(n=31)$. This wasn't the case for the majority ( $n=124,3$ missing cases). Only one participant reported that they had a disability 
that affected their ability to commute/travel unaided, while 2 participants reported that they had a disability that affected their ability to use/work on a computer without additional adjustments.

\section{Results}

\subsection{Descriptive Characteristics and Correlations}

The scales tended to perform relatively well with reliability coefficients largely over 0.7 (Nunnally 1978). Table 1 provides an overview of the correlations between all single-item and composite scales. The correlations indicated that goal clarity was positively correlated with support satisfaction $(r=0.301, p<0.001)$, feeling valued $(r=0.533, p<0.001)$, and self-reported job performance $(r=0.237, p=0.003)$. Satisfaction was also positively correlated with performance $(r=0.319, p<0.001)$.

Several possible control variables were identified. Age is known to correlate with job tenure and often status, both of which are known to influence training satisfaction as well (Schmidt 2009). However, this variable did not correlate with any of the measures in Table 1. Categorical control variables such as gender and information received ahead of time were not included in Table 1. Similarly, goal clarity may have been particularly important where participants had only a partial or incomplete understanding of the tasks to be completed. Further analysis using a means test showed no significant gender differences in relation to any of the variables listed in Table $1(p=n s)$. An analysis of variance did show, however, that goal clarity $(F(3,151)=5.80, p=0.001)$ and appreciation reported by e-interns $(F(3,151)=5.78$, $p=0.001)$ differed depending on the amount of information received ahead of time. Most notably, Bonferroni's post-hoc comparison suggested those who had all necessary information consistently reported higher goal clarity or appreciation than those who had no or only some information. As a result, information received ahead of time was retained as a significant control variable. Country was considered as potential covariate, however, the large majority (127 of 154 available nationality reports) came from India, reducing the potential usefulness of this variable as a control variable.

Table 1. Correlations for measures.

\begin{tabular}{cccccc}
\hline & $\mathbf{1}$ & $\mathbf{2}$ & $\mathbf{3}$ & $\mathbf{4}$ & $\mathbf{5}$ \\
\hline Support satisfaction & 1 & & & & \\
Goal clarity & $0.301^{* *}$ & 1 & & & \\
Appreciation (feeling valued) & $0.533^{* *}$ & $0.508^{* *}$ & 1 & & \\
Perceived job perform & $0.319^{* *}$ & $0.237^{* *}$ & $0.536^{* *}$ & 1 & \\
Age & 0.112 & -0.013 & 0.149 & 0.084 & 1 \\
\hline & Note: ${ }^{* *} p<0.01$.
\end{tabular}

\subsection{Reward and Effort Conditions}

The allocation of participants to the effort conditions was decided based on participants' scores below and above the mean (for all participants) on two measures: Goal clarity $(M=3.36, S D=0.88)$ and overall support obtained (e.g., from peers, supervisor, organization; $M=3.15, S D=0.54$ ). This was based on suggestions by Dysvik et al. (2010) that when training is perceived as both relevant and supportive, participants may also be willing to reciprocate (see also (Batson 1987)).

We added the two scale means for each participant and used the mean generated for this new combined measure, we identified those below the mean $(M=6.51, S D=1.16$, median $=6.50)$ as being in the high effort group (reporting lower goal clarity and satisfaction, $n=82$ ) and those above the mean as being in the low effort group (reporting higher goal clarity and satisfaction $n=76$ ).

The allocation of participants to reward conditions was based on two measures: Training opportunity and remuneration. When candidates were neither trained nor paid, they were allocated to the low reward condition $(n=61)$. If they were trained (and in 21 cases also paid), they were allocated to the high reward condition $(n=97)$. An overview is provided in Table 2. 
Table 2. Cell sizes in different conditions $(N=158)$.

\begin{tabular}{cccc}
\hline \multirow{2}{*}{ Reward Conditions } & \multicolumn{2}{c}{ Effort Conditions } & \multirow{2}{*}{ Subtotal } \\
\cline { 2 - 3 } & High & Low & \\
\hline Low (no training or payment) & $36(22.8 \%)$ & $25(15.8 \%)$ & 61 \\
High (trained and more) & $46(29.1 \%)$ & $51(32.3 \%)$ & 76 \\
Subtotal & 82 & 76 & 158 \\
\hline
\end{tabular}

\subsection{Group Differences}

In order to explore the effect of conditions, we utilized analysis of variance. The allocation to the group conditions was not random, as situation in which the use of ANOVA has been criticized as not appropriate (see also (Miller and Chapman 2001)). However, the provisions of training to e-interns were not under the control of the experimenter or interns, but subject to the organization in question. The results showed a significant difference in terms of appreciation (feeling valued) and self-reported job performance. The descriptives clearly show that the average for e-interns in the two high effort conditions compared to the two low effort conditions (regardless of reward condition) generally reported feeling less valued, and as performing at lower levels than their counterparts who were in the low effort conditions. This supports H1. Being in a high reward condition did seem to matter as well. Regardless of being in high or low effort conditions, participants in the high reward conditions reported higher values on average than those in the low reward conditions, supporting $\mathrm{H} 2$. We also considered potential covariates such as age and information received ahead of time, but found that their inclusion made very little difference to the actual results. The results of the post-hoc analysis and ANCOVA for covariates are presented below the Table 3.

Table 3. Analysis of variance and descriptive results.

\begin{tabular}{|c|c|c|c|c|c|}
\hline \multirow[b]{2}{*}{ Dependent var.s } & \multirow[b]{2}{*}{ ANOVA } & \multicolumn{2}{|c|}{ High Effort (HE) Mean (SD) } & \multicolumn{2}{|c|}{ Low Effort (LE) Mean (SD) } \\
\hline & & $\begin{array}{l}\text { Low Reward } \\
\text { (LR) }\end{array}$ & $\begin{array}{c}\text { High Reward } \\
\text { (HR) }\end{array}$ & $\begin{array}{l}\text { Low Reward } \\
\text { (LR) }\end{array}$ & $\begin{array}{l}\text { High Reward } \\
\text { (HR) }\end{array}$ \\
\hline Feeling valued & $\begin{array}{c}F(3,154)=17.86 \\
p<0.001, \eta_{p}^{2}=0.26^{a}\end{array}$ & $\begin{array}{l}2.98 \\
(0.63)\end{array}$ & $\begin{array}{l}3.04 \\
(0.75)\end{array}$ & $\begin{array}{l}3.49 \\
(0.76)\end{array}$ & $\begin{array}{l}3.89 \\
(0.60)\end{array}$ \\
\hline $\begin{array}{l}\text { Perceived job } \\
\text { performance }\end{array}$ & $\begin{array}{c}F(3,154)=4.78, \\
p=0.003, \eta_{p}^{2}=0.08^{b}\end{array}$ & $\begin{array}{c}2.42 \\
(0.73)\end{array}$ & $\begin{array}{c}2.50 \\
(0.69)\end{array}$ & $\begin{array}{c}2.60 \\
(0.64)\end{array}$ & $\begin{array}{c}2.94 \\
(0.76)\end{array}$ \\
\hline
\end{tabular}

Notes: The descriptives include $M(S D)$. Results are shown without covariates. ${ }^{\text {a }}$ Post-hoc analysis showed that HE/LR differed from LE/LR $(p=0.059)$. HE/HR differed from both LE/LR $(p=0.040)$ as well as LE/HR $(p<0.001)$. $\mathrm{HE} / \mathrm{LR}$ and HR/HR were not significantly different. The inclusion of age and information available ahead of time $(p<0.05)$ in a follow-up ANCOVA did not change the model results $(p<0.001)$; ${ }^{\mathrm{b}}$ Post-hoc comparison showed that HE/LR differed from LE/HR $(p=0.006)$. And HE/HR differed from LE/HR $(p=0.017)$. The inclusion of information received ahead of time in a follow-up ANCOVA reduced the $p$-value from 0.003 to 0.013 (but did not change the significance of the model overall).

The results suggest that in both the case of appreciation and perceived job performance, those individuals who fell into the low effort and high reward conditions had higher values than those other e-internships. The range for appreciation (feeling valued) included one additional answering option compared to job performance, which explains why the bars were higher on average.

\section{Discussion}

The goal of the current paper was to introduce readers to the training experience of interns in e-internships. We hope that this information reassures educators and employers that e-internships provide training opportunities to students and prospective employees. Our findings suggest training comes in numerous forms and may therefore add experience value to prospective applicants' resumes. In addition, the relatively mixed reports about self-reported performance suggest that the e-interns did not inflate their own performance reports as these ranged from unsatisfactory to excellent. 


\subsection{Main Summary of Findings}

Based on the preceding literature around low reward and high effort conditions and the impact on employee well-being and health, we hypothesized that such conditions might also have an impact on e-interns' sense of appreciation and performance. In line with Siegrist's (1996) effort-reward imbalance model, it was hypothesized that appreciation (the feeling of being valued) and self-reported performance would be higher when e-interns are in a high effort (H1) and high reward (H2) condition, compared to a low effort or low reward condition. Using self-reports from a cross-sectional sample of e-interns, several effort and reward conditions were created. These conditions were developed using the premises of expectancy theory. The results supported a significant influence of e-internship conditions. Individuals in high effort conditions involving lower goal clarity and less support reported that they were less productive (in terms of job performance). They also felt less appreciated than their counterparts in low effort conditions.

However, in both low effort and high reward conditions, the outcomes tended to be more positive for e-interns overall. If e-internships featured high goal clarity and support (in line with the low effort condition) and these e-interns were further offered rewards (training and potentially remuneration), they felt more valued and appreciated. Their self-reported performance was also higher compared to the reports of other e-interns in the other conditions.

These findings are in line with the effort-reward imbalance model by Siegrist (1996), but also considering his imbalance framework in relation to self-reported performance indicators and appreciation (feeling valued). Our results indicate that low-reward and high-effort conditions create negative self-reported performance outcomes and have a significant impact on interns' feeling of being valued or appreciation. This is also in line with work that has connected self-rated performance to perceived equitable rewards (Mullins and Christy 2016). Individuals forms implicit notions about the type of rewards they deserve, often commensurate with the demands placed on them. It therefore makes sense that e-interns who receive less desirable outcomes (such as pay or training) but have to expend more energy on accomplishing their tasks would report less positive feelings about the experience. The effort-reward imbalance model (Siegrist 1996) proposes that when efforts are not reciprocated, stress arises due to the lack of rewards. Feeling less appreciated and valued may be the first step towards trying harder to do well against increasingly difficult odds, setting the stage for future stress and potentially even burn-out. While the latter may be less likely in transitional and often temporary e-internships, identifying the sources of effort-reward imbalances may be a first step towards rebalancing provisions to match requirements (e.g., in the form of training needs analysis, socio-technical job design).

The findings of our study also align with several notions of the expectancy framework by Vroom (1964) which emphasizes the links between effort, performance and rewards. The link to instrumentality as proposed by Vroom (1964) is also maintained, as the appreciation variable was measured using a short career instrumentality scale. However, our study did not address valence per se, as the value of rewards to e-interns was not differentiated or further explored (the focus was on payment or non-payment only). It can be assumed that being paid is being valued more by e-interns than those not being remunerated by the internship provider. Nevertheless, it is worth considering that what is valued is subject to the individual being asked - as the desirability of a reward may vary from one individual to the next (see. Porter and Lawler's (1968) expectancy model). For example, an individual that has already completed a specific type of training may find a review of such training less rewarding than one who identifies the need for such training.

\subsection{Practical Contributions and Implications}

The findings contribute to this field of research on two fronts. First, the present study makes an important contribution to our knowledge about the real-world learning opportunities inherent in e-internships based on a real study of e-interns. Our results suggest that e-internship provide interns with, not necessarily, any better or worse experience than they might have had in any traditional, 
location-bound internship. Many of the same aspects matter. Achieving goal clarity, providing support, and creating circumstances that ensure employees are rewarded for their efforts are aspects important to all internships. Second, the present results also speak to the wider applicability of Siegrist's (1996) conceptualization of high and low effort and reward conditions to a computer-mediated setting such as e-internships.

The findings have practical implications. In order to overcome concerns about the usefulness of e-interns, it will be important to employers seeking e-interns to clearly outline the learning or training aspects. Not only will this attract more interest among e-interns, it may also support their efforts to gain academic credit for internships related to their degree or modules. Expectation management may play another important role in providing goal clarity and support, and could also trigger a first discussion around the training needs of e-interns and provisions to address these, if possible. Ayyagari et al. (2011, p. 853) suggested that "by managing expectations, individuals might perceive lower demands on their resources, leading to lower perceptions of work overload." Expectation management may reduce ambiguity and uncertainty about responsibilities and performance thresholds, thus reducing the effort involved for e-interns to achieve task performance. In addition, focused discussions around expectations provide employers with a means to assess their capability and resources to meet these expectations during the e-internship. If this discussion is captured in reports to the university, educators may also be more open to accrediting such learning experiences. Their influence may positively contribute to greater standardization among e-internship providers in terms of e-intern recruitment, training and appraisal, a potentially significant side benefit for small employers who are still in the process of developing their human resource practices.

More discussions and pilot projects among e-internship providers, educators, and e-interns may help to identify and set the stage for mutual benefits. Academics working in universities and private consultancies appear to play a key role in establishing such pilot projects and bridges between universities and employers. In some cases, successful relations between university departments and start-ups founded by alumni have also generated new collaborations in support of e-internship and accredited learning. According to the verbal reports of some interns and employers, a number of e-internship providers have already managed to set up good collaborations with universities, utilizing the institution's internship forms or module evaluation materials to support project reports and feedback to educators about the performance of their e-interns when academic credit is an option. Such collaboration requires both educators and e-internship providers to exchange findings and explore these options together. We hope that our findings contribute to this exchange.

Finally, we would like to suggest a number of approaches that could help improve e-internship success. Realistic job previews of new candidates, regular appraisals of individuals and teams, frequent project meetings and reviews of reward practices could help maintain a performance-supporting balance between the efforts required to succeed and the varying outcomes for both the individuals and organizations. Universities often have the staff, facilities and resources to support such activities via their online conference platforms. A closer cooperation of departments, career services and e-internship providers might be required to combine such resources effectively. Given that many universities already accredit work-based learning (often in form of continuous professional development courses), recruit international students and have overseas locations, they may too have access to a number of knowledgeable experts within their own institutions who could support accreditation efforts of e-internships in their own country and abroad.

\subsection{Limitations}

A number of concerns apply. Two methodological limitations regard the use of single-item measures and the shortening of measures. In the current case, job performance as reported by our interns was measured by single items. The use of single-item indicators in marketing research has been discussed in the literature on previous occasions (see also (Petrescu 2013)). These may be used when there is only one indicator available when the concepts of interest are simple rather than complex 
(Petrescu 2013). In the current case, there were no pre-existing scales that had already been employed within the context of e-internships. In addition, the use of such indicators using single indicators was considered optimal in the study given the length of the survey. Some of the reliability values were lower than desirable, although Nunnally (1967) has argued that for exploratory research, a reliability of 0.6 would be sufficient, although he argues that the standard ought to be higher at 0.7 (Nunnally 1978). The decision to reduce the length of pre-existing scales were based on two considerations. First, it was important to minimize the length of the survey and fatigue due to long questionnaires. The drawback here is that shortening scales might affect internal consistency (see also (Stanton et al. 2002)) while scales based on items with dichotomous response options and fewer items often tend to have lower reliability (Peterson 1994). Second, judgmental item qualities such as relevance to the study and population of interest was a key concern. Many excluded items referenced contextual or behavioral elements that were not relevant to the virtual work context. Rather than designing all items ourselves, we preferred to utilize items that were relevant to e-internships and still referenced the main concept of interest (such as goal clarity). However, we acknowledge that the use of such shortened scales reduces the possibility of including articles for comparative purposes (e.g., Angoff 1996).

A number of sample and data source restrictions apply. Given the large variety (and small case numbers) of countries, it was not possible to examine country differences. This includes the possibility of self-selection bias. Past work on person-environment fit has suggested that when the personal characteristics of an individual and the environmental requirements result in a perceived lack of fit, they may experience significant strain due to unmet individual needs and job demands (see Cooper et al. 2001). This suggests that many participants may have included individuals more or less tolerant of ambiguity, but further research is needed to test this possibility.

In terms of training, we only have some indication of the goals for some of the training e-interns received. Many of the training goals (introduction to team work, the value of the organization, and so on) could be readily delivered via e-coaching and e-mentoring based on conference software (Smith and Israel 2010). Nevertheless, on-the-job training is an important form of training in many small businesses and among manufacturers when they wish to increase skills and train in new technologies (Blanchard and Thacker 2009; Choi et al. 2015). The job instruction technique is ideal for skill development, but would require a presentation forum of some kind and feedback from the instructor. All findings were self-reported, we did not have any supervisor-generated and hence lack of information about the frequency of supervisory feedback (see also (Beausaert et al. 2011)). In this study, it was not possible to explore the dyadic interactions between e-interns and supervisors. This would have been helpful to better understand the type and form of training delivery as well as the varying learning benefits associated with these.

\subsection{Future Avenues for Research and Practice}

A number of potential areas of research remain. We list a few knowledge gaps for consideration. For example, it would be interesting to see to what extent growth and relatedness needs (Alderfer 1969) predict perceived appreciation and the evaluation of e-internships generally. This could help us understand withdrawal and drop-outs in e-internships, and potentially also help to predict tenure of other professionals in virtual work situations. Second, the e-interns' perceptions of 'reward power' (French Jr. and Raven 1968) of the e-internship providers may also be worth studying to understand whether or not e-interns adjust their evaluation of rewards based on the organizational circumstances and the organization's perceived ability to reward e-interns. Many e-interns worked for small or medium-sized companies; it is unclear if their reward expectancies differ from e-interns working for larger organizations. In addition, we know very little about the extent to which accreditation of e-internship experiences by educators would shift recruitment in favor of smaller employers who often struggle to attract potential talent. Since many universities aim to support entrepreneurs and start-ups (many of which will be alumni), accrediting and supporting e-internships within their regions may be a particularly promising way to link talent to future employers who already have a link to the university. 
Third, many rewards usually presented to office workers are integral to e-internships (see overview of conventional rewards in (Arnold et al. 2010)). We expect that access to personal learning opportunities and mentors within organizations may be more highly valued by virtual workers and e-interns since these may be more difficult to access than other traditional rewards. An exploration of different forms of extrinsic regulation (see Ryan and Deci 2000) may help to understand which rewards work best for individuals who cherish recognition and accomplishment compared to individuals that prefer traditional rewards such as pay (Rynes et al. 2004). This could also help to identify which rewards would be most attractive for what kind of e-intern. External accreditation by a university may potentially function as an important form of reward for e-interns who are still studying. Such reward strategy may also help streamline training programs and potentially even help identify readily available resources that universities have on hand (e.g., software and expert advice) and that could be supportive of e-internship training efforts.

Acknowledgments: No funding was received for this research. We gratefully acknowledge the support of all our participants, several website administrator, e-internship providers, and university ambassadors. Without their engagement and the interest in this work, we would not have been able to reach so many e-interns. Thank you for your time, feedback and support!

Author Contributions: The original survey and study was designed by both authors. The recruitment and data analysis was managed by the first author. The publication was produced by the first author in collaboration with the second author.

Conflicts of Interest: The authors declare no conflict of interest.

\section{References}

Alderfer, Clayton. 1969. An empirical test of a new theory of human needs. Organizational Behavior and Human Performance 4: 142-75. [CrossRef]

Angoff, William H. 1996. Equating. In Educational Measurement: Origins, Theories, and Explications, Vol. 2: Theories and Applications. Edited by Annie W. Ward and Howard Stoker. Lanham: University Press of America, pp. 259-331.

Arnold, John, Ray Randall, Joanne Silvester, Fiona Patterson, Ivan Robertson, and Cary Cooper. 2010. Work Psychology. Understanding Human Behaviour in the Workplace, 5th ed. Harlow: Pearson Education Ltd.

Ayyagari, Ramakrishna, Varun Grover, and Russell Purvis. 2011. Technostress: Technological antecedents and implications. MIS Quarterly 35: 831-58. [CrossRef]

Batson, C. Daniel. 1987. Prosocial motivation: Is it ever truly altruistic? Advances in Experimental Social Psychology 20: $65-122$.

Beausaert, Simon, Mien Segers, and Wim Gijselaers. 2011. The use of a personal development plan and the undertaking of learning activities, expertise-growth, flexibility and performance: The role of supporting assessment conditions. Human Resource Development International 14: 527-43. [CrossRef]

Bergman, Mindy E., Michelle A. Donovan, Fritz Drasgow, Randall C. Overton, and Jaime B. Henning. 2008. Test of Motowidlo et al.'s (1997) theory of individual differences in task and contextual performance. Human Performance 21: 227-53. [CrossRef]

Blanchard, P. Nick, and James W. Thacker. 2009. Effective Training, Systems, Strategies, and Practices, 4th ed. Harlow: Pearson Prentice Hall.

Chen, Hai-Ming, and Yi-Hua Hsieh. 2006. Key trends of the total reward system in the 21st century. Compensation and Benefits Review 38: 64-70. [CrossRef]

Choi, Young Jun, Chan Lee, and Ronald L. Jacobs. 2015. The hierarchical linear relationship among structured on-the-job training activities, trainee characteristics, trainer characteristics, training environment characteristics, and organizational characteristics of workers in small and medium-sized enterprises. Human Resource Development International 18: 499-520. [CrossRef]

CIPD. 2014. Strategic Reward and Total Reward, CIPD Factsheet. London: Chartered Institute of Personnel and Development, March.

Cooper, Cary L., Phillip J. Dewe, and Michael P. O'Driscoll. 2001. Organizational Stress. Thousand Oaks: Sage Publications. 
De Jonge, Jan, Hans Bosma, Richard Peter, and Johannes Siegrist. 2000. Job strain, effort-reward imbalance and employee well-being: A large-scale cross-sectional study. Social Science E Medicine 50: 1317-27. [CrossRef]

Derycke, Hanne, Peter Vlerick, Bart van de Ven, Isabel Rots, and Els Clays. 2013. The impact of effort-reward imbalance and learning motivation on teachers' sickness absence. Stress and Health 29: 14-21. [CrossRef] [PubMed]

Dysvik, Anders, Bård Kuvaas, and Robert Buch. 2010. Trainee programme reactions and work performance: The moderating role of intrinsic motivation. Human Resource Development International 13: 409-23. [CrossRef]

Feldman, Daniel C., William R. Folks, and William H. Turnley. 1999. Mentor-Protege Diversity and Its Impact on International Internship Experiences. Journal of Organizational Behavior 20: 597-611. [CrossRef]

French Jr., John R. P., and Bertram H. Raven. 1968. The Bases of Social Power. In Group Dynamics: Research and Theory, 3rd ed. Edited by Dorwin Cartwright and Alvin Frederick Zander. New York: Harper \& Row, pp. 259-69.

Jeske, Debora, and Carolyn Axtell. 2014. e-Internships: Prevalence, characteristics and role of student perspectives. Internet Research 24: 457-73. [CrossRef]

Jeske, Debora, and Carolyn Axtell. 2016a. Global in small steps: e-internships in SMEs. Organizational Dynamics 45: 55-63. [CrossRef]

Jeske, Debora, and Carolyn Axtell. 2016b. How to run successful e-internships: A case for organizational learning. Development and Learning in Organizations: An International Journal 30: 18-21. [CrossRef]

Johnson, Stefanie K., Kenneth Bettenhausen, and Ellie Gibbons. 2009. Realities of working in virtual teams: Affective and attitudinal outcomes of using computer-mediated communication. Small Group Research 40: 623-49. [CrossRef]

Korsgaard, M. Audrey, Bruce M. Meglino, Scott W. Lester, and Sophia S. Jeong. 2010. Paying you back or paying me forward: Understanding rewarded and unrewarded organizational citizenship behavior. Journal of Applied Psychology 95: 277-90. [CrossRef] [PubMed]

Lim, Doo Hun, and Michael Lane Morris. 2006. Influence of trainee characteristics, instructional satisfaction, and organizational climate on perceived learning and training transfer. Human Resource Development Quarterly 17: 85-115. [CrossRef]

Lunenburg, Fred C. 2011. Expectancy theory of motivation: Motivating by altering expectations. International Journal of Management, Business, and Administration 15: 1-6.

Mabey, Christopher. 2001. Closing the circle: Participant views of a 360-degree feedback programme. Human Resource Management Journal 11: 41-53. [CrossRef]

Miller, Gregory A., and Jean P. Chapman. 2001. Misunderstanding analysis of covariance. Journal of Abnormal Psychology 110: 40-48. [CrossRef] [PubMed]

Mullins, Laurie J., and Gill Christy. 2016. Management and Organisational Behaviour, 11th ed. Harlow: Pearson Education Limited.

Nunnally, Jum C. 1967. Psychometric Theory. New York: McGraw-Hill.

Nunnally, Jum C. 1978. Psychometric Theory, 2nd ed. New York: McGraw-Hill.

Peterson, R. A. 1994. A meta-analysis of Cronbach's coefficient alpha. Journal of Consumer Research 21: 381-91. [CrossRef]

Petrescu, M. 2013. Marketing research using single-item indicators in structural equation models. Journal of Marketing Analytics 1: 99-117. [CrossRef]

Porter, Lyman W., and Edward E. Lawler. 1968. Managerial Attitudes and Performance. Homewood: R. D. Irwin.

Rizzo, John R., Robert J. House, and Sidney I. Lirtzman. 1970. Role conflict and ambiguity in complex organizations. Administrative Science Quarterly 15: 150-63. [CrossRef]

Rothmann, Ian, and Cary L. Cooper. 2015. Work and Organizational Psychology, 2nd ed.London and New York: Routledge. Ryan, Richard M., and Edward L. Deci. 2000. Intrinsic and extrinsic motivations: Classic definitions and new directions. Contemporary Educational Psychology 25: 54-67. [CrossRef] [PubMed]

Rynes, Sara L., Barry Gerhart, and Kathleen Minette A. 2004. The importance of pay in employee motivation: Discrepancies between what people say and what they do. Human Resource Management 43: 381-94. [CrossRef]

Schmidt, Steven W. 2009. Employee demographics and job training satisfaction: the relationship between dimensions of diversity and satisfaction with job training. Human Resource Development International 12: 297-312. [CrossRef] 
Siegrist, Johannes. 1996. Adverse health effects of high-effort/low-reward conditions. Journal of Occupational Health Psychology 1: 27-41. [CrossRef] [PubMed]

Smith, Sean J., and Maya Israel. 2010. e-Mentoring: Enhancing special education teacher induction. Special Education Leadership 23: 30-40.

Stanton, Jeffrey M., Evan F. Sinar, William K. Balzer, and Patricia C. Smith. 2002. Issues and strategies for reducing the length of self-report scales. Personnel Psychology 55: 167-94. [CrossRef]

Szymanski, Dawn M., Jovanovic Jelena Ozegovic, Julia C. Phillips, and Melissa Briggs-Phillips. 2007. Fostering scholarly productivity through academic and internship research training environments. Training and Education in Professional Psychology 1: 135-46. [CrossRef]

Tsutsumi, Akizumi, and Norito Kawakami. 2004. A review of empirical studies on the model of effort-reward imbalance at work: Reducing occupational stress by implementing a new theory. Social Science E Medicine 59: 2335-59. [CrossRef]

Van Vegchel, Natasja, Jan de Jonge, Hans Bosma, and Wilmar Schaufeli. 2005. Reviewing the effort-reward imbalance model: Drawing up the balance of 45 empirical studies. Social Science E Medicine 60: 1117-31. [CrossRef]

Vroom, Victor H. 1964. Work and Motivation. New York: Wiley.

(c) 2017 by the authors. Licensee MDPI, Basel, Switzerland. This article is an open access article distributed under the terms and conditions of the Creative Commons Attribution (CC BY) license (http://creativecommons.org/licenses/by/4.0/). 